\title{
THE NEED FOR ETHICAL DEVELOPMENT IN IT CURRICULUM
}

\author{
Cynthia. J Gormley, D.Sc. Robert Morris University, cjgst16@mail.rnu.edu \\ SamanthaJ.Gormley, Robert Morris University,sjgst19@mail.rmu.edu
}

\begin{abstract}
Ethical practices are an experienced and a taught behavior. From birth, we develop the sense of "right and wrong". As humans develop in a culture, the perception of what is ethical may be related to the understanding of what should be done. From a business viewpoint, IT professionals are often involved in decision making due to their dynamic role in development. It is important that trained business practitioners are committed to ethical behavior. With the immediate and ongoing advancements in technology, it is vital that ethics are applied to IT professional practice and in the decision making process. This paper will examine the psychological perspective, cultural development, teaching approach, steps to consider when designing an ethical IT program and conclude with a legitimate discussion on ethical practices.
\end{abstract}

Keywords: Ethics, Ethical practices, Ethical Curriculum, IT Ethics

\section{INTRODUCTION}

We learn about theory, principles, and reasoning of ethics, however the culture and environment in which we live often determine the ethical behavior of a person. "As we learn from our experiences, we become embedded in lifelong ethical education that contributes to our growth and development or, in Deleuze's words, 'becoming the other' in the midst of experimental, problematic and shocking events" [20]. We are faced with unscrupulous decisions others make that impact us, then as an individual, and part of a culture, we need to not only attempt to understand the travesty and process it, but still be able to continue to make moral and ethical decisions. This ground level approach to life is found at the intersection of personal, academic, environment/culture and beliefs; what we will call ethics.

This paper will discuss the process of ethical development. Theories on why ethics should be included in core curricula for technology programs, and consideration to the claim that "information is not knowledge, of course, and without ethical and intellectual judgment - which cannot be programmed into a machine - the Age of Information is an Age of ignorance" [18] are presented to support the need for ethical instruction in IT programs. The argument is most business schools teach ethics, journalism classes require an ethical framework, and ethics is typically offered as a course in universities. Often part of the decision making or creative teams include information systems, programmers and developers. For this reason and others, the criterion of how ethics should be reinforced in the technology field is deliberated. Psychological perspective, cultural development, teaching approach, and concepts to consider when designing an ethical IT program will be discussed. After the theory and basic concepts of ethics and perspectives, a discussion will include the need for advancement in teaching ethics in IT and any curricula, as a business model and for societal progression.

For the purpose of this paper, the focus will be on the simplistic definitions of behavior, ethics and ethical. Behavior, as defined by Mariam Webster [21], is: (a) the manner of conducting oneself (b) Anything that an organism does involving action and response to stimulation (c) the response of an individual, group, or species to its environment business definition A response of an individual or group to an action, environment, person, or stimulus. The definition of Ethics is (a) an area of study that deals with ideas about what is good and bad behavior: a branch of philosophy dealing with what is morally right or wrong (b): a belief that something is very important. Ethical follows the same concept, as defined: following accepted rules of behavior: morally right and good.

\section{PSYCHOLOGICAL PERSPECTIVE}

Individual moral actions vary. Action and reaction to situations help to mold the concept of right from wrong. "Human beings achieve moral maturity though attending to concrete details as well. We are not all clones" [1]. It is important to maintain the balance, "individuating is as essential for moral health as integration" [1]. Parenting, 


\section{Issues in Information Systems \\ Volume 15, Issue I, pp. 162-169, 2014}

family practices, interaction at a young age produces varied results. "We require different responsibilities, personal destinies, and relationships in the course of growing up which may be unique for each person" [1]. As a child, we learn what to do by observing others and being told what is right. The observation of others is often what gets us into trouble as a child. As we grow, our world becomes larger as we start relating to other people, for example school age. Then we form relationships, work and personal. The development of this process is explained as "NeoKohlbergian" approach as proposed by Rest, Bebeau and Thomas (1999) develops the moral process into three phases [1]:

1. Personal interest stage: one's moral development, individual moral considerations and generally confined to self, family, and friends. Moral direction is perceived.

2. Maintaining Norm's stage: extends moral considerations beyond the small group of face-to-face actors and begins to consider his or her roles in the wider setting. The "us and them" mentality, conformity to one's behavior absent of critical thinking.

3. Post conventional thinking: a person begins to think in truly independent ways. Common good, greatest good for all, actualizing personhood and intimacy among people.

This three dimension model approach, as enhanced by Brady and Hart, describes the layering of the two theories and relates to the total development or better understanding of "how human beings mature ethically throughout their lives and in a way that provides more breadth than is typically provided by stage development theorists" [1]. This details the original three moral processes into a more refined explanation, titled Deontological, Teleological and Axiological theories. The particulars of each theory are [1]:

Deontological theory: obligations or duties, universal or particular, a search for principles of action that all people should adopt personal responsibilities which are carved out by the details of a situation and of a person's life. In the absence of principles, personal responsibilities become the focus of ethical thought.

Teleological theory: Purpose or goals, standards of right and wrong, required, sense of direction, pursuit of personal authenticity, more impressed with personal goals, human perfectibility is not universal, and it is different for every person.

Axiological theory: Values, a more intimate approach to ethics, what should one value? The common good, what a person relates to and without which one might feel impoverished.

Based on this concept, it is easily understood how dissimilar reasoning and development of ethics are achieved. Adding into this would be environment/culture, and where the person is morally at that point in life, based on the theory they possess or lack.

This model was expanded by Brady and Hart due to "The micro-moral aspects of ethical theory have generally received less philosophical attention in the literature, partly because particulars are a 'problem' for macro-moral ethicists, who have manifest a centuries-long preference for universals" [1]. Expanding on the micro-moral aspects was the "Six Voices Model" as stated by Brady and Hart to be more beneficial due to the liberal approach and "pays more attention to the "micro-morality' questions mentioned by Rest et al (1999)" [1]. "Voices rather than theories because some of the positions identified (below) are regarded as full blown theories in ethics, others seen more like 'casts of mind' or 'outlooks' depending on the nature of the development and presentation of each voice historically [1]. The theory relates to the ongoing issues of applying ethical practices to problems. Pointing out that each issue can be distortedly framed to be good practicing ethics, even though it defaces the true meaning of ethical.

Putting this theory into perspective, consider the processes as the physical body transforms. Behavior is taught similarly to how the body is fed. "Ethical theory has much to gain from stage developmental psychology ..." [1]. Growing, developing and evolving ethically is the process that is experienced as well as taught. Human development excels when the "...maturing process simultaneously puts into motion two diverging processes in the human moral development. One is the integrating process, well studied in both ethical theory and developmental psychology, in which a person increasingly broadens his or her ability to consider a wider array of evidence, circumstances, and variances of all kinds" [1]. The psychological factors and theories offer a basis for what is included as basic concepts for each element. While this is an elementary outline of the theories, it is important to acknowledge that there are factors considered for each element that create the process. The insights of each theory give perspective, knowing there is a need for a defined progression and that the process is complex. It is important to understand the concepts that produce the development as well as the actual human experience. This is where culture becomes the next step in understanding the need for ethical education. 


\section{CULTURAL DEVELOPMENT}

As determined, external forces form a large part of the ethical balance created in each individual. We witness a disaster, see the horror in it but process the reasoning individually. Greif, sadness, overwhelming feelings, relief, or even joy may be experienced by individuals sharing the same experience. "We can also see that human action (cognitive or ethical) is essentially a free act" [14]. Consider the global ramifications if an ethical balance is not achieved. "...different cultural values make people disagree rather than agree" [8]. The Ethical Dilemma, as explained by Maxwell is "defined as an undesirable or unpleasant choice relating to a moral principle or practice" for one of three reasons: 1) We do what's most convenient 2) We do what we must to win and 3) We rationalize our choices with relativity [12]. We can always produce a logical reason for doing something, ethical or not.

In discussing ethical behavior in current time, there are dilemmas we face that did not exist before with the advancement of technology. How age groups may perceive ethical behavior is as varied as the situation itself. For example, this study examines student's perception about ethical behavior: "With respect to cheating using IT (Muir 2006) reported on a survey of Canadian students, who thought stealing software from a store was a serious offence; but only $40 \%$ of these students thought that illegally downloading software from the internet is stealing [15]. To examine a different IT component, in 1999 almost $49 \%$ admit to cutting and pasting information off the internet, and in "2005, a majority of the students (77\%) believe such cheating is not a very serious issue" [15].

As individuals, students develop their place in society and continue to develop even out of the academic environment. As they develop ethically, they are learning a skill. "Skills and virtues are involved as apprentices learn a craft though adopting the values of the practice. Craft is a practice-a specific term used to denote the setting in which people live and work." [12]. We attempt to teach the skill while teaching ethics but changes transpire often a rapid or at a hurried pace, and some principles are deteriorated in the process. Implications by Nordkvelle and Olson discussed the use of computers and perception of doing work slower before the technology was developed. If we had issues before were they magnified due to the speed of technology? "Computers allow us to do what we did before only more so-so if we did not do well before (ICT) we may do worse with it. Or we may do better. We need to think about this as teachers." [12]. Hofstede and Hofstede pointed out "There are technology-induced problems. In the past when a new technology had been invented, it could also be applied. This is no longer the case, and decisions have to be made whether some of the things humans can make should be made, if so, subject to precautions" [8]. Eminent ethical decisions must be made, for the good of all cultures and for the "survival of mankind" [8]. This is something as parents, teachers, responsible members of society, we must always consider. This is a core reason why ethics should be taught to all practices at all levels, it is responsibility.

Taking this notion to the next generation, how will our students react or act in a work environment? Will they be ethically grounded or will the pressurized environment dissolve their ethical decision making practice? "Workers after all might have other ideas about how to produce woven goods based on other precepts, which do not accord with automation and its rationale" [16]. The line where technologies are used to produce a better product or become an ethical issue rather than a technological advancement can often be gray. For example, the advancement or production of software. Is it the ethical decisions of the software developer and the company that sells the software that may produce a negative culture or outcome or is the end user of the product who may misinterpret the product? This may even be related to educational software for children.

As future leaders, ethical decision making skills are essential to IT students. As an example, Hudson states "being honest is not always as easy as it sounds. Leaders have information that they may not be able to share with everyone at the same time: for example, plans for restructuring staff, discussions about a potential contract, or disciplinary matters" [10]. As unethical as it may seem, the lack of transparency is a process, with information being released at the right time. "However, hiding decisions or conversations will damage the trust and respect that people have in their leaders" [10]. Is the easy way out simply to be unethical? "Many people believe that embracing ethics would limit their options, their opportunities, their very ability to succeed in business" [12]. The question here is, does being honest jeopardize the business or is the "need to know" principle of a business a necessity to maintain status quo. Not every employee needs to know what the boss is thinking but does need to know that ethical decisions are 


\section{Issues in Information Systems \\ Volume 15, Issue I, pp. 162-169, 2014}

being made to ensure growth, safety and security. Respect for the employees and reciprocation to the executive level is justified.

Internal disruption of a company could produce an environment we do not have our students equipped to navigate such as "Employees lay the blame for ethical breeches on management pressure that focuses in the bottom-line performance rather than a balance caring for the shareholders and sensitivity towards the employees." [6] There is acknowledgement of an ethical dilemma but is there proactive results to remove the unethical practice. If there is recourse, "Management blames the competitive environment, where global companies have fewer restrictions and can better compete in the world, in effect saying 'if we do not match their tactics, we will fail as companies and then we will not be fulfilling our fiduciary responsibilities to our owners and to the communities in which we live" [6]. This reasoning may be an unrealistic response based on "fairness and justice can be relevant to long-tern economic benefits" [3]. It should be noted that as teachers we need to reinforce "image a caring and concern for any endeavor (a direct outcome of the concern for fairness or justice) builds goodwill and reputation, which is likely to enhance economic profits in a long run" [3]. Maxwell noted five factors that are perceived when a person violates their ethical behavior: 1) Pressure, 2) Pleasure 3) Power, 4) Pride and 5) Priorities [12].

In a technology environment, change is constant. Better, faster, and more are common terms used for the advancement of creating the latest and greatest efficient product. "The concept of fairness implicitly assumes that one needs to have a complete picture of the surrounding reality and move away from overtly objective and rationalistic interpretations of individuals" [3].

\section{TEACHING APPROACH}

Once we recognize the need for an understanding of cultural focus, goals, and values consider the academic process to which we study and relate to Ethics as a subject. "Teaching is rooted fundamentally in ethics" [14]. Ethical Awareness is developed through life, as we have determined. "Teachers should be exposed to the fundamentals of (Deleuze's) philosophy and ethics starting as early as pre- (school) level and also in the form of continuous professional development so as to incorporate it in their classrooms" [20]. As academic instruments teachers are often the person providing the image of "ethical" to a student. "The experiences that produce shock to thought are conducive to learning ethical education." [20]. We review the Enron reports, talk endlessly about the Exxon Valdez oil spill and discuss the negative images in the papers, but is this enough to teach ethical practices? "Teachers need to examine the moral values inherent in their practices and use those values for debate" [16]. The struggles of dayto-day teaching varies from classroom to classroom, teacher to teacher and student to student. Mgombelo states teaching is an action, not a knowledge base [14]. Debate the topics the students will understand. Connect real life to the discussions. The question is "can we teach character?" [6]. Even though Ethics is an everyday topic, "...there is a moral aspect of almost everything we do" (Nodding's evaluation on Dewey's philosophy on action 1988) [16]. Ethical decision making is everyday life. Considering the debated theories in this paper, the notion of the individual, being instructed to develop the traits of a strong character explains the need for students to be instructed on acceptable practices to develop a healthy ethical practice.

Character, simply defined by Mariam Webster [21] is "the way someone thinks, feels, and behaves: someone's personality". Gilacalone and Thompson state "in reality the values that an individual holds fast are central to the development of character, and character leads to behaviors" [6]. Going from the individual to the process, is a moving target. Students come together with varied concepts of behavior and ethical philosophies, how may a teacher determine the best course of action on this moving target.

Carroll detailed "Ethics textbooks generally explore three key principles—rights, justice and utilitarianism—and some ethics educators also discuss the Golden Rule' [2]. Textbooks give only a small part of what is needed to understand the ethics concept. Students are often confused or leery to take a stand due to thinking unlike others. "What students also learn in ethics class is that some of their classmates view topics much differently than they do, which is an essential truth for managers attempting to resolve ethical dilemmas in the workplace. Most often, students come to this realization through case study decisions, when they discover that not everyone else has responded to a particular set of circumstances in the same way they have. Realizing that the world is full of people with differing viewpoints..." [2]. His perspective on teaching ethics was outlined in the seven possible outcomes for the classroom experience in learning ethics [2]: 
1. Greater awareness of the ethical aspects of a business situation

2. Ethical concepts that will help me analyze decisions

3. Ethical principles that can help me make better decisions

4. Ways to become a more ethical person

5. Reasons my classmates see things so differently

6. Reasons my classmates see things so similarly

7. I'm not sure what I learned in this class

While considering the possible outcomes for the classroom, Carroll also stated "Discovering what and how students learn in ethics courses enables professors to design even more effective courses" [2]. Often students are not advanced enough to understand to complex situations, and ethical dilemmas are not always obvious to the student however future unethical practices are unknown. They cannot always be projected and panned for. Carroll observed "Just as important as discovering what students learned was discovering how they learned." Students ranked their choices of how they were instructed [2]:

1. Lectures/presentations by the instructor

2. Instructor-led discussions after student case presentations

3. My own reading of texts/articles prior to class

4. Studying for and taking the exams

5. Case presentations by student groups

6. My own reading and studying prior to class

Students did learn by being taught. By lectures, reading, studying, they declared the comprehension of ethical practices. In addition to Carroll's research, a recent studies suggest that Christian colleges and universities have either responded positively to the calls for the reintegration of moral curriculum or always resisted its marginalization." [6]. We are not just considering the school in general, but public, private or Christian may play a factor in how ethics is approached. Regardless of the school, college or university, Carroll explains concepts such as "integrity strategy", "descriptive versus normative ethics", "stakeholder management", "business ethics" and "moral development" [2] can be helpful for students as they develop their careers. To understand the consequences of practices that may impact the person as an individual. The additional knowledge to program would incorporate ethical decision making and ethical approach to analytical analysis as well.

From a unitary perspective, "three approaches of educational ethics can be identified" as stated by [14]:

1. "Thou shall not" or moral codes that form an ethical law. In education ethical codes would be rules, rights and ways to protect members of the community. (Judeo-Christian)

2. Good as a benefit to the minority or majority. Who is the beneficiary of the benefit, a calculation of the decision? (Unitarianism)

3. Fictitious nature of truth, do not impose our rules onto others (Postmodern)

However, Mgombelo quickly points out that teaching "does not rely on rules or moral codes reflected in the above approaches" [14]. In evaluating her decision making process for moral or ethical conclusions, Mgombelo stated her action is not based on the approaches, "I just act" [14]. Only after her reaction does she make the decision about the approach she has used.

In business, Maxwell frames a logical approach as to how people would want to be treated. This approach is easily transferable to any framework of human interaction. Six common ideals of how we all would like to be treated [10]:

1. I want to be valued

2. I want to be appreciated

3. I want to be trusted

4. I want to be respected

5. I want to be understood

6. I do not want others to take advantage of me

Included in this discussion would be the difference between ethical rules and ethical principles [11, 13]. Kitcherner's Five Principles for Ethical Decision Making are: 


\section{Issues in Information Systems \\ Volume 15, Issue I, pp. 162-169, 2014}

1. Respecting Autonomy: The right to act as a free agent. Make their own decisions, and respond to others actions as they see suitable.

2. Doing No Harm: Consider all individuals when making a decision. This would include physical, psychological, or to an individual's self-worth.

3. Benefiting Others: Promote health and wellbeing to everyone involved. Provide a balance the potential good and bad.

4. Being Just: To treat fairly, treat equal, threat others the way you would want to be treated.

5. Being Faithful: Trustworthy, keep promises and respect others

\section{CONSIDERATIONS WHEN DEVELOPING AN ETHICAL IT PROGRAM}

“...a question is not whether ethics can be taught, but whether ethics can be learned in the classroom?" [2].

There is a belief that IT and Business share a Code of Ethics. Both require ethical behavior and practices, professionals share solutions and development. "As the environment of business grows ever more complex, especially the development and provision of information technology, and more global, the need for one comprehensive code of ethics for IT professionals becomes even more advisable" [17].

Creating the ethical person is not only a process but a developmental system. “...social engineering had been eclipsed, as we are painful aware, by political conservatism, intent on side-stepping culture and history by focusing on 'learning technologies' such as the computer" [18]. Social engineering is the "human engineering-appears to assume that education is like a complex automobile engine: if only we make the right adjustments - in teaching, in learning, in assessment-it will him, and transport us to our destination..." [18]. Understanding the psychological makeup of an individual, putting that person into a context of a culture or society then forming that person into a responsible human being with morals and acceptable social behavior is a great responsibility for a teacher. Combine that with infusing the quality education for the student to succeed and a skill to become not only self-sufficient but a viable part of society is a monumental task.

As we have determined, ethics is absorbed everywhere, not just the classroom. Barriers may be already in place when the student walks into the first ethics course. Years of backfilled experiences may taint the objectivity of the student. It is the responsibility of the teacher to expose that student to ethical awareness. In order to develop a course, take the culture into consideration as well as the individual. To make an ethical course better, Giacalone and Thompson [6] recommend making the course count by:

1. An aspirational approach to ethics is advocated. A vision of more than doom is needed, not to make people feel stupid or guilty. Focus on the positive. Foster well-being of people and their environment. This will make people more than honest decision makers, it will produce concern for their community, quality of life and social responsibility.

2. Think global. Consider global order, give an active voice to values $>$ Not to just understand but create an environment that will produce higher ethical values for all. Positive role models, positive leadership, to go beyond performance and create highly respectable realizations.

3. Engage a larger audience. We do not teach bashing of business and capitalism, we should be teaching how to build bridges to enhance and create the environment that brings to light the conditions that students will face at the 'real world'.

4. Understand how the organization builds an ethical environment and build the process that will support human development. Promote ethical behavior, support people, worldview of human values and do this with more than lectures or signed promises. The example given was whistleblower policy. This policy helps detect unethical behavior.

Also take into consideration these Six Questions designed by Davis, M \& Keefer, M. [4]:

1. How do I know when a new profession needs an ethical program?

2. How can I convince the profession of the need for an ethics program?

3. How do I identify the professions chief ethical problems?

4. How do I identify the ethical principles to resolve those problems?

5. How do I create an ethics curriculum and guide instruction?

6 . What will I have when I have everything I need? 
Another way to organize an IT ethics program would be to include these suggested factors for an IT department [5]:

1. Establish organizational roles to manage ethical issues

1. Schedule ongoing assessment of ethic requirements

2. Establish required operating values and behaviors

3. Align organizational behaviors with operating values

4. Develop awareness and sensitivity to ethical issues

5. Integrate ethical guidelines to decision making

6. Structure mechanisms to resolve ethical dilemmas

7. Facilitate ongoing evaluation and updates to the program

8. Help convince employees that attention to ethics is not just a knee-jerk reaction done to get out of trouble or to improve one's corporate or public image

Examine the individuals and what is currently happening in the global environment. "Both what is 'cultural' and what is 'ethical' depends on cultural value positions" [8]. Keep the Golden Rule in mind when creating a healthy ethics course. Maxwell [12] outlines this approach:

1. What can I do for you?

2. Make character decisions

3. Sacrifice finances for family

4. Develop relationships with actions

5. Possess 'others first' mindset

6. Count your friends

7. Base their worth on their values

Service-learning has been researched and is an option for ethical conveyance. "The implications are numerous for service-learning as a delivery method for ethical development objectives, ethical education and ethics training" [9]. This method is based on six individual intensity factors: 1) magnitude of consequence 2) social consensus 3) probability effect 4) temporal immediacy 5) proximity and 6) concentration of effect [9]. For future ethical decision making abilities, Hoyt stated "an additional implication is based on the potential of service learning to develop perceived behavioral control...the skill set for ethical decision making can be used to predict future ethical behavior when those future dilemmas are not yet known" [9]. It was established, based on this research, that service learning can be more intense related to ethical behavior, more predictable perceived behavior and increases the goal of making ethical decisions [9].

An example of a course created to discuss ethics was "Frameworks for Decision-Making: Ethical Perspectives" [19]. Although this course is structured for leadership graduate programs, the "ethical Perspectives are regarded as an essential element of a well-considered decision making process" [19]. The course description includes an environmental framework, exploration of ethical reasoning, analysis of ethical dilemmas and cases, discussion of abstract concepts, ethical issues prompted by movies, private narration of individual concerns, and projects. The program incorporates the four distinct ethical paradigms: Ethic of Care, Ethic of Critique, Ethic of the Profession and Ethic of Justice [19]. The goal is to "take a rational approach to making ethical decisions, but resentment, prejudices, personal dislikes, and a range of human emotions have a way of distorting reality" [19].

Another option while developing an ethical course is to consider the Professional Codes of Ethics. Association of Information Technology Professionals (AITP), Independent Computer Consultants (ICCA), Information Systems Security Association (ISSA), Association for Computer Operations Management (AFCOM) and Computing Technology Industry Association (CompTIA) have codes in place. Introduction to these organizations and their practices may be beneficial to the students and to the development of the course.

Some final questions should be asked in this process: What makes a respectable ethics teacher? Training, awareness, and the ability to transfer not just knowledge but a behavior, a culture, and ethical bearings. Think about the ethical experiences you as a person or teacher you had. How did you handle them? What decisions did you make and were they good ethical decisions? Based on what we discussed, are you ethically grounded? We, as part of human race, 


\section{Issues in Information Systems \\ Volume 15, Issue I, pp. 162-169, 2014}

have many barriers and blurred perceptions of being or doing "good". Sad to say we will always have the "Enron's" to discuss, but how real are they to the average student? Relate to what they know. Discuss their reality with them, give them a personal goal or vision of what being ethically balanced means. It is our ethical responsibility to create the environment that decision makers of the future can prosper and evolve into a better society for all of mankind.

\section{REFERENCES}

1. Brady, N \& Hart, D. (2007) An Exploration into the Developmental Psychology of Ethical Theory with Implications for Business Practice and Pedagogy. Journal of Business Ethics Vol. 76 pp. 397-412 DOI 101007/s10551-006-9290-3

2. Carroll, A. (2005) An Ethical Education. BizEd (AACSB International) January/February 2005 pp. 36-40.

3. Chaterjee, S., Suprateek, S, \& Fuller, M. (2009). Ethical Information Systems Development: A Baumanian Postmodernist Perspective. Journal of the Association for Information Systems. Vol. 10, Special Issue, pp. 787815.

4. Davis, M \& Keefer, M. (2013). Getting Started: Helping a New Profession Develop an Ethics Program. Science and Engineering Ethics. Vol. 19: pp. 259-264. DOI: 10.1007/s11948-011-9279x

5. Garcia-Jay, T., Grupe, F. \& Kuechler, W. Is it time for an IT Ethics Program?

6. Giacalone, R \& Thompson, K. (2006). From the Guest Co:Editors: Special Issue on Ethics and Social Responsibility. Academy of Management Learning \& Education. Vol. 5, No. 3, pp. 261-265.

7. Glanzer, P., Ream, T., Villarreal, P. \& Davis, E. (2004) The teaching of Ethics in Christian Higher Education: An Examination if General Education requirements, Journal of General Education, Vol. 53 No. 3-4, 184-200.

8. Hofstede, G \& Hofstede, G. (2005). Culture and Organizations—Software of the Mind. New York, NY: McGraw-Hill

9. Hoyt, B. (2011). A Research study in the Ethics Educational and Training: Predicting Ethical Behavior. International Journal of Education Research. Vol. 6, No. 1, pp. 97-117.

10. Hudson, M. (2005). Managing at the Leading Edge. San Francisco, CA: Josey-Bass.

11. Kitchener, K. (1985). Ethical Principles and Ethical Decisions in Student Affairs. Applied Ethics in Student Services. Jossey-Bass: San Francisco, CA

12. Maxwell, J. (2003). There is no such thing as Business Ethics. USA: AOL Time Warner Book Group

13. McDonald, W., Ebelhar, M., Orehovec, E. \&Sanderson, R. (2006). Ethical Decision Making: A Teaching and Learning Model for Graduate Students and New Professionals. The College Student Affairs Journal. Vol. 25, Issue 2, pp.152-163.

14. Mgombelo, J. (2006). Teaching and Ethics in Complex Science: The Ethics of Absolute Unitary Being. Complicity: An International Journal of Complexity and Education. Vol. 3, No. 1, pp. 21-38.

15. Molnar, K., Kletke, M. \& Chongwatpol, J. (2008). Ethics vs. IT Ethics: Do Undergraduate Students Perceive a Difference? Journal of Business Ethics. Vol. 83. 657-671 DOI:10.1007/s10551-007-9643-3

16. Nordkvelle, Y. \& Olson, J. (2005) Visions for ICT, Ethics and the Practice of Teachers. Education and Information technologies. 10:1/2, pp. 19-30.

17. Payne, D. \& Landry, B. (2005). Similarities in Business and IT Professional Ethics: The Need for and Development of a Comprehensive Code of Ethics. Journal of Business Ethics. Vol. 62, pp. 73-85. DOI: 10.1007/s10551-005-3439-3

18. Pinar, W. The Problem with Curriculum and Pedagogy. Journal of Curriculum and Pedagogy. pp. 67-82.

19. Reardon, R.M. (2013). Towards Best Practice in Ethics Education for Scholarly Practionier of Leadership: An Undistorted view of Reality. Planning and Changing. Vol. 44, No. 3/4, pp. 286-307.

20. Semetsky, I. (2012). Living, learning, loving: Constructing a new ethics of integration in education. Discourse: Studies in the Cultural Politics of Education. Vol. 33 February, pp. 47-59.

21. Webster Dictionary. http://www.merriam-webster.com/dictionary 